(6) OPEN ACCESS

- Additional material is published online only. To view please visit the journal online (http://dx.doi.org/10.1136/ gutjnl-2014-306768).

Department of Medicine III, Division of Gastroenterology and Hepatology and Christian Doppler Laboratory for Molecular Cancer Chemoprevention, Medical University of Vienna, Vienna, Austria

\section{Correspondence to} Professor Christoph Gasche, Division of Gastroenterology and Hepatology, Medical University of Vienna,

Währinger Gürtel 18-20A1090, Vienna A-1090, Austria; christoph.gasche@meduniwien. ac.at

KD and VK contributed equally.

Received 10 January 2014 Revised 7 April 2014 Accepted 10 April 2014 Published Online First 8 May 2014

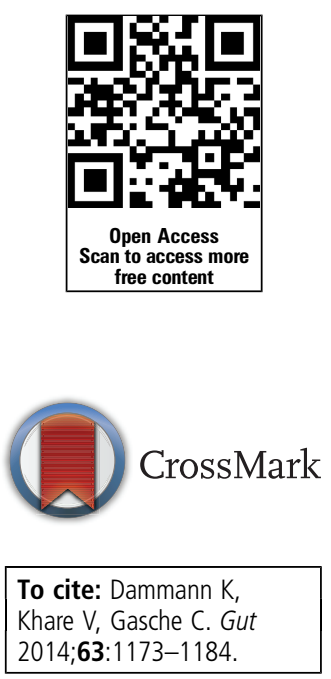

\title{
Tracing PAKs from GI inflammation to cancer
}

\author{
Kyle Dammann, Vineeta Khare, Christoph Gasche
}

\section{ABSTRACT}

P-21 activated kinases (PAKs) are effectors of Rac1/ $\mathrm{Cdc42}$ which coordinate signals from the cell membrane to the nucleus. Activation of PAKs drive important signalling pathways including mitogen activated protein kinase, phospoinositide 3-kinase (PI3K/AKT), NF-KB and Wnt/B-catenin. Intestinal PAK1 expression increases with inflammation and malignant transformation, although the biological relevance of PAKs in the development and progression of $\mathrm{Gl}$ disease is only incompletely understood. This review highlights the importance of altered PAK activation within GI inflammation, emphasises its effect on oncogenic signalling and discusses PAKs as therapeutic targets of chemoprevention.

\section{INTRODUCTION}

Most GI disorders are triggered by three main denominators: the environment (Western lifestyle), gut microbiota and genetic susceptibility. Such genes control various gut functions such as control of GI inflammation and tumourigenesis. Alterations in GI homeostasis via disruption of cell polarisation, proliferation, differentiation and apoptosis are associated with disease. One, albeit not fully appreciated, group of key regulators of diverse gut functions includes the p-21 activated kinases (PAKs). PAKs are involved in the innate immune response, barrier function, maintenance of crypt proliferation, epithelial cell migration and cell survival. ${ }^{12}$ As PAKs are nodal kinases orchestrating multiple signalling cascades, they are attractive targets for therapeutic intervention. ${ }^{3}$

PAKs are highly conserved serine/threonine kinases from Saccharomyces cerevisiae to Homo sapiens. ${ }^{4} 5$ Mammals have six different PAKs which are classified based on their homology into group I (PAK1-PAK3) and group II (PAK4-PAK6) ${ }^{1}$ (table 1). Interestingly, Drosophila only has three PAKs, in which two are homologous to group I, and one homologous to group II. ${ }^{6}$ Overall, PAK1 and PAK4 are the most investigated of all PAKs, and have been brought into

Table 1 Overview of groups I and II P-21 activated kinase (PAK) chromosomal location

\begin{tabular}{lll}
\hline Gene & Chromosomal location & \\
\cline { 2 - 3 } Name & Homo sapiens & Mus musculus \\
\hline PAK1 & $11 q 13-q 14$ & 7 E2 \\
PAK2 & $3 q 29$ & 16 B2 \\
PAK3 & Xq23 & X F2 \\
PAK4 & $19 q 13.2$ & 7 A3 \\
PAK5 & $20 p 12$ & 2 F3 \\
PAK6 & $15 q 14$ & 2 E5 \\
\hline
\end{tabular}

focus due to their association with various malignancies. ${ }^{1}$ PAK overexpression contributes to tumour invasiveness in uveal melanoma, ${ }^{7}{ }^{8}$ neurofibromatosis, ${ }^{9}$ breast, ${ }^{10}{ }^{11}$ cervical, ${ }^{12}$ colon, ${ }^{13}{ }^{14}$ oesophageal, ${ }^{15}$ gastric, ${ }^{16}{ }^{17}$ hepatic, ${ }^{18}$ lung, ${ }^{19}$ ovarian, ${ }^{20}$ prostate $^{21} 22$ and thyroid cancer. ${ }^{23}$ PAKs were also correlated to inflammatory diseases such as rheumatoid arthritis ${ }^{24}$ and asthma. ${ }^{25}$ Here we highlight the importance of PAK activation and their role in the pathogenesis of GI inflammation and malignant transformation. Our focus is built around PAK1, although the significance of other PAKs in GI disease has also been brought into context.

\section{STRUCTURE AND ACTIVATION OF PAKS}

The PAK1 gene in $H$ sapiens is located on chromosome $11 \mathrm{q} 13.5$ and includes 20 different splice variants. $^{26}$ The largest isoform consists of 14 exons and encodes 545 amino acids. ${ }^{26}{ }^{27}$ It is under transcriptional control of Forkhead Homeobox type O (FOXO) transcription factors which directly interact with the PAK1 promoter. ${ }^{28}$ PAK4 is located on $19 \mathrm{q} 13.2$, includes 13 splice variants, the largest of which consists of eight exons, and encodes 591 amino acids. ${ }^{26}$

Crystal structure revealed three conserved domains in all group I PAKs. The N-terminus contains a regulatory domain comprising a protein binding domain (PBD) that overlaps with an autoinhibitory domain (AID) and a kinase domain at the C-terminus (figure 1). The AID provides an auto-inhibited homodimer where the AID of one PAK molecule overlaps with the kinase domain of the other. ${ }^{29}$ Recently, it was shown that group II PAKs also contain a sequence-related AID, although they do not form auto-inhibited homodimers. ${ }^{30}$ Additionally, proline-rich sequences within the regulatory domain facilitate interactions with $\mathrm{SH} 3$ domain containing adapter molecules (figure 1A).

PAK activation is complex and is initiated via GTPases, membranous phoshoinositides, adaptor proteins, growth factors and effectors of intestinal bacteria such as the enterohaemorrhagic Escherichia coli O157:H7 type III effector EspG. ${ }^{1}{ }^{3}{ }^{3}{ }^{32}$ Rho GTPases Cdc42/Rac1, as well as Wrch- $1,{ }^{33}$ directly bind to group I PAKs within the N-terminal PBD, also referred as the GTPase binding domain or Cdc42/Rac1-interactive binding (CRIB). ${ }^{5}$ Subsequent auto-phosphorylation at multiple $\mathrm{N}$-terminal residues releases the dimer and initiates $\mathrm{C}$-terminal kinase activation (figure 1B). Phosphorylation at residue Thr-423 is critical for the maintenance and stability of PAK1 activation. ${ }^{5}$ Group II PAKs have a higher specificity to $\mathrm{Cdc} 42$ in comparison with Rac1. Interestingly, PAK4 is constitutively phosphorylated at Ser474, but only becomes activated upon Cdc42 binding. ${ }^{30} \mathrm{Cdc} 42$ also regulates the cellular localisation of PAK4. ${ }^{34} 35$ 
A

Group I PAK

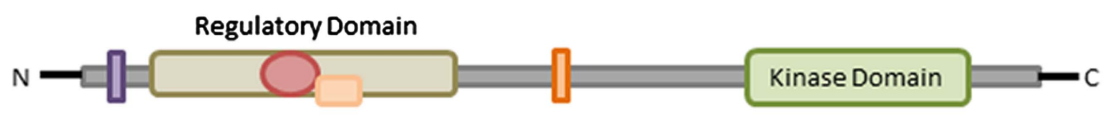

Group II PAK

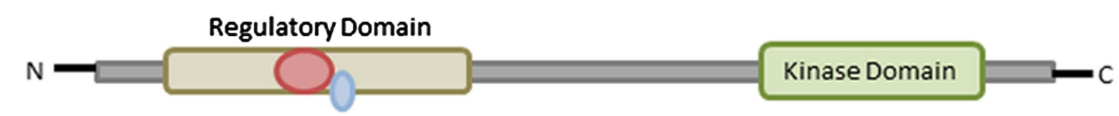

GTPase binding domain (GBD)

Autoinhibitory domain (AID)

Autoinhibitory pseudosubstrate motif

\section{NCK binding site}

PIX binding site

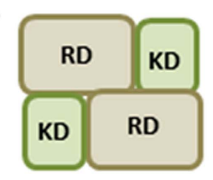

Inactive
GTPase

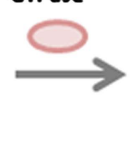

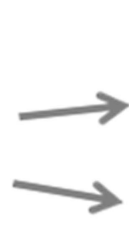

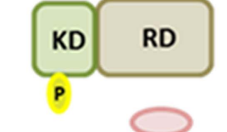

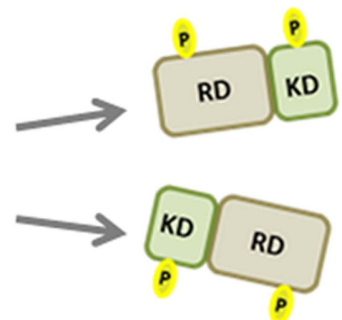

Active

Regulatory Domain (RD)

Kinase Domain (KD)

Figure 1 Structure and activation of P-21 activated kinase (PAK)1. (A) Based on structural and biochemical studies, the mechanism of PAK activation is conserved in group I. The N-terminal auto-inhibitory domain (AID) keeps PAK1 as a dimer in an auto-inhibited state, blocking substrate binding through stabilisation of an inactive conformation. The AID partially overlaps with the GTPase binding domain. (B) GTP-bound Rho GTPases (Cdc42/Rac1) releases PAK1 from its auto-inhibitory conformation, allowing its auto-phosphorylation (Thr-423). Phosphorylation at Thr-423 is critical for PAK1 activity. Subsequently, additional residues are phosphorylated at N-terminus, blocking auto-inhibition.

Selyunin and Alto recently identified an alternative mechanism of group I PAK activation by EspG, a virulence effector protein from enterohaemorrhagic E coli. ${ }^{32}$ EspG directly binds the AID in a region independent from the CRIB domain to disrupt the homodimer and initiate PAK activation. ${ }^{31}$

Membranous phosphoinositides such as phosphatidylinositol 4,5-bisphosphate bind to the $\mathrm{N}$-terminal basic region of PAK1 and assist in Rac1-mediated activation. ${ }^{36}$ Sphingosine disrupts PAK1's auto-inhibited state and the enzyme 3-phosphoinositidedependent kinase-1 (PDK1) directly phosphorylates PAK1 at Thr-423. ${ }^{37}$

Adaptor proteins such as growth factor receptor-bound protein 2 (GRB2), ${ }^{38}$ PAK-interactive exchange factor (PIX) ${ }^{39}$ and $\mathrm{Nck}^{40}$ interact with proline-rich motifs of PAK1, thereby recruiting PAK1 dimers to the membrane and increasing their interaction with GTPases and lipids. Adaptor proteins also influence PAK1's localisation within the cytoplasm or within the nucleus. ${ }^{41}$ Growth factors such as epidermal growth factor (EGF) or hepatocyte growth factor (HGF) also contribute to PAK activation. EGF activates the protein kinase $\mathrm{CK} 2$ which phosphorylates PAK1 at S-223 and contributes to its kinase activation ${ }^{42}$ whereas HGF initiates PAK4 kinase activation through a phospoinositide 3-kinase (PI3K)-AKT2 mechanism which lacks clarity. ${ }^{43}$ The extracellular matrix glycoprotein vitronectin also activates PAK4, and stimulates its migration from the cytoplasm to the membrane. ${ }^{45} 46$

\section{PAK PHYSIOLOGY: KINASE VERSUS SCAFFOLDING FUNCTIONS}

PAKs are predominantly located in the cytoplasm, although they have roles at the membrane and within the nucleus. PAK1 has both kinase dependent and independent functions in controlling cytoskeletal dynamics, cell migration, influencing mitosis and survival. ${ }^{1}$

\section{Cytoskeletal dynamics}

PAK1's role in cytoskeletal remodelling includes the phosphorylation of multiple targets as well as protein-protein interactions independent of its kinase activity. PAK1 facilitates actin stabilisation through phosphorylation of myosin light chain (MLC), LIM kinase, filamin A and dynein light chain 1 (DLC1). ${ }^{47} 48$ PAK1 contributes to microtubule disassembly via phosphorylating stathmin (STMN) and tubulin $\mathrm{B}^{48}$ Lamellipodia formation and membrane ruffling still occur in PAK1 kinase mutants; thus, PAK1's PBD regulates cytoskeletal remodelling in absence of an activated kinase. ${ }^{49}$ The role of PAK4 in cytoskeletal reorganisation has also been demonstrated and is mechanistically different from group I PAKs. PAK4 does not phosphorylate MLCK; instead, Cdc42 recruits PAK4 to the Golgi and induces polymerisation of actin and the formation of filopodia. ${ }^{50}$ PAK4 kinase dead mutants were shown to block filopodia formation; 
however, stimulation of PAK4 kinase activity was not sufficient to alter cytoskeletal dynamics in the absence of $\mathrm{Cdc} 42 .{ }^{35}$

\section{Switching from adherence to migration}

Cell migration involves cytoskeletal rearrangements in addition to turnover of focal adhesion contacts to the stroma at the leading edge of the cell. ${ }^{51}$ PAK 1 translocation to the membrane via adaptor proteins influences such turnover of focal adhesion contacts via phosphorylation of focal adhesion kinase (FAK). ${ }^{52}$ Wound healing assays have demonstrated that a multiprotein complex including PAK1, PIX and G-protein receptor kinase interactor 1 (GIT1) translocates from focal adhesion contacts to cell-to-cell contacts in order to initiate wound closure and contact inhibition. ${ }^{53}$ Intestinal epithelial cells must also balance signalling between focal adhesion contacts at the stroma and cell-to-cell contacts such as adherens junctions (AJ). Cadherins such as E-cadherin are a critical component of AJ, and control the localisation of the PAK1-PIX-GIT1 complex at focal adhesion contacts. This complex may contribute to a crosstalk between AJ and focal adhesion contacts. ${ }^{54}$ PAK1 regulates E-cadherin transcription, albeit through a separate pathway. PAK1 phosphorylates and activates Snail, a transcriptional repressor of E-cadherin. ${ }^{55}$ PAK4 overexpression leads to the disassembly of stress fibres and focal adhesion contacts thereby promoting anchorage independent growth. ${ }^{50} \mathrm{HGF}$ induces an interaction between GRB2-associated binding protein 1 (Gab1) and PAK4 at the cell periphery, and disruption of the Gab1PAK4 complex impeded cell migration and invasion. ${ }^{56}$ PAK4 activation by vitronectin increases cell motility. Specifically, PAK4 increases integrin $\alpha v \beta 5$ turnover, disrupts actin-integrin complex and weakens cell adhesion. ${ }^{45}$

\section{PAK nuclear translocation and its regulatory effects on transcription}

Growth factors such as EGF induce the translocation of PAK1 to the nucleus. PAK1 has three nuclear localisation signals (NLS1-NLS3). ${ }^{57}$ Its nuclear translocation requires binding of DLC1 to activated PAK1. ${ }^{58}$ Activation of PAK1 facilitates an interaction between NLS2 and importin to induce its nuclear translocation. ${ }^{57}$ PAK4 includes both nuclear localisation and nuclear export signals. Nuclear import of PAK4 requires an interaction with $\alpha 5$ importin, and its export is through the chromosome region maintenance-1 pathway. ${ }^{59}$ PAK1 has differential effects on gene transcription. Chromatin immunoprecipitation assays revealed that PAK1 directly binds to and represses transcription of the nuclear factor of activated T cell (NFAT-1) gene, as well as upregulating transcription of phosphofructokinase, although indirectly as a component of a transcriptional complex. ${ }^{57}$ PAK1 can inhibit and activate transcriptional corepressors and transcription factors. The corepressor C-terminal binding protein 1 is inhibited by PAK1, while SMRT/ HDAC1-associated repressor protein is activated. ${ }^{48}$ PAK1 also inhibits FOXO by phosphorylation, which acts as a negative feedback loop for its own transcription. ${ }^{60}$ Phosphorylation of histone $\mathrm{H} 3$ by PAK1 may provide an unspecific mechanism by which PAK1 influences gene transcription. ${ }^{48}$ Both PAK1 and PAK4 are involved in post-transcriptional regulation; for example, PAK1 phosphorylates Poly-c-RNA binding protein (PCBP1) which increases its nuclear localisation and activity. ${ }^{61}$ PAK4 includes a ribonucleoprotein (RNP) interacting region which associates with RNPs and RNA binding proteins to regulate translation as well as nuclear/cytoplasmic transport. ${ }^{62}$ Within the nucleus, PAKs have diverse actions in modulating transcription of multiple targets. However, in the context of GI disease, the positive and negative cellular consequences of nuclear PAK have yet to be defined.

\section{Downstream of RAS}

Receptor tyrosine kinase activation of RAS leads to the activation of multiple signalling cascades, including the activation of PAK1. ${ }^{1}$ Inversely, PAK1 knockout (KO) mice (which have no distinct phenotype) display reduced expression of RAS key effectors including ERK and AKT within the colon. ${ }^{63}{ }^{64}$ PAK4 KO mice are embryonically lethal. ${ }^{65}$ Cellular knockdown of PAK4 also impeded ERK signalling in vitro. ${ }^{66}$ PAK1 activates mitogen activated protein kinase (MAPK)/ERK signalling via phosphorylation of RAF, MEK and ERK, as well as forming proteinprotein interactions in the absence of its kinase activity. ${ }^{67} 68$ PAK4 is located downstream of AKT; ${ }^{43}$ however, PAK1 is centralised between RAS and PI3K/AKT. Within the PI3K/AKT cascade, PAK1 plays another key role via scaffolding PDK1, thereby facilitating phosphorylation of $\mathrm{AKT}^{69}$ In a positive feedback loop, both PDK1 and AKT phosphorylate and activate PAK1 ${ }^{37} 70$ (figure 2).

\section{Activation of $\boldsymbol{\beta}$-catenin}

The Wnt/ $\beta$-catenin pathway is a key process in GI development and homeostasis. ${ }^{71}$ Intestinal LGR $5^{+}$stem cells use Wnt signalling for continual regeneration. ${ }^{71}{ }^{72} \beta$-Catenin is the key effector of the Wnt signal, and regulates transcription of Wnt target genes when bound to the $\mathrm{T}$ cell factor (TCF) or lymphoid enhancer factor (LEF) family of transcription factors. Importantly, $\beta$-catenin drives canonical Wnt signalling through Rac1. $^{73}$ The Rac1 effector, PAK1, directly interacts with $\beta$-catenin and regulates its transcriptional activity through phosphorylation at Ser-663 and Ser-675 $5^{13}{ }^{74}$ (figure 3). PAK1 KO mice in an adenomatous polyposis coli (APC) wildtype background displayed a marked reduction in nuclear $\beta$-catenin expression. ${ }^{63}$ PAK4 phosphorylates $\beta$-catenin at ser-675, and colocalises with $\beta$-catenin in the nucleus thereby increasing TCF/LEF transcriptional activation. ${ }^{59} \beta$-Catenin is an effector of Wnt, and plays a role in cell-to-cell contacts as a complex with E-cadherin at AJ. ${ }^{75}$ Inhibition of PAK1 increased the membranous localisation of both $\beta$-catenin and E-cadherin, ${ }^{76}$ thereby increasing the formation of $\mathrm{AJ}$ and reducing intestinal permeability. This further underlines the role of PAK1 in intestinal integrity and mucosal barrier function.

\section{Upstream of NF-кB}

Rac1 is also a key activator of the NF- $\kappa \mathrm{B}$, which orchestrates a cellular inflammatory response and promotes tumourigenesis. $^{77} 78$ Tumour necrosis factor (TNF) $\alpha$ or interleukin (IL)-1 $\beta$ stimulate canonical NF- $\mathrm{B}$ signalling, whereas, lipopolysaccharide (LPS) or lymphotoxin B activates the non-canonical pathway (figure 4). ${ }^{79}$ LPS has been shown to activate both canonical and non-canonical NF- $\kappa$ B, albeit through different cascades. ${ }^{80}$ Both pathways regulate transcription of multiple genes which activate or suppress proliferation, apoptosis or cytokine production. Activation of NF- $\mathrm{BB}$ has also been correlated to mucosal barrier dysfunction $^{8182}$ further implicating the importance of NF- $\mathrm{KB}$ in GI homeostasis.

Several studies have investigated the interaction of PAK1 and $\mathrm{NF}-\kappa \mathrm{B}$ activation. The AKT-PAK1 cascade is required for NF- $\kappa \mathrm{B}$ signalling in epithelial cells stimulated with HGF, which itself stimulates PAK1. ${ }^{83}$ Another study implicated that PAK1 regulates multiple NF- $\mathrm{BB}$ signalling cascades in fibroblasts. ${ }^{85}$ PAK1 was also found to regulate non-canonical signalling via activation of $\mathrm{NF}-\kappa \mathrm{B}$ interacting kinase $(\mathrm{NIK}){ }^{86}$ PAK1 activates 
Figure 2 P-21 activated kinase (PAK) 1 signalling downstream of receptor tyrosine kinases (RTK). RAS activation initiates PAK1, RAF/mitogen activated protein kinase (MAPK) and phospoinositide 3-kinase (PI3K)/AKT signalling. Activation of PAK1 by epidermal growth factor induces its by RAS may provide a positive feedback loop to further activate MAPK and PI3K. Importantly, PAK1 allocates crosstalk between the PI3K and MAPK pathways. PAK1 may induce MEK1/2 or ERK1/2 independent of RAF, as well as increase PI3K/AKT signalling by scaffolding PDK1 to increase phosphorylation of AKT. In turn, PDK1 may also directly phosphorylate and activate PAK1. PAK1 signalling may activate pro-inflammatory or pro-survival pathways by facilitating nuclear activation of NF- $\kappa B$. nuclear translocation. PAK1 activation
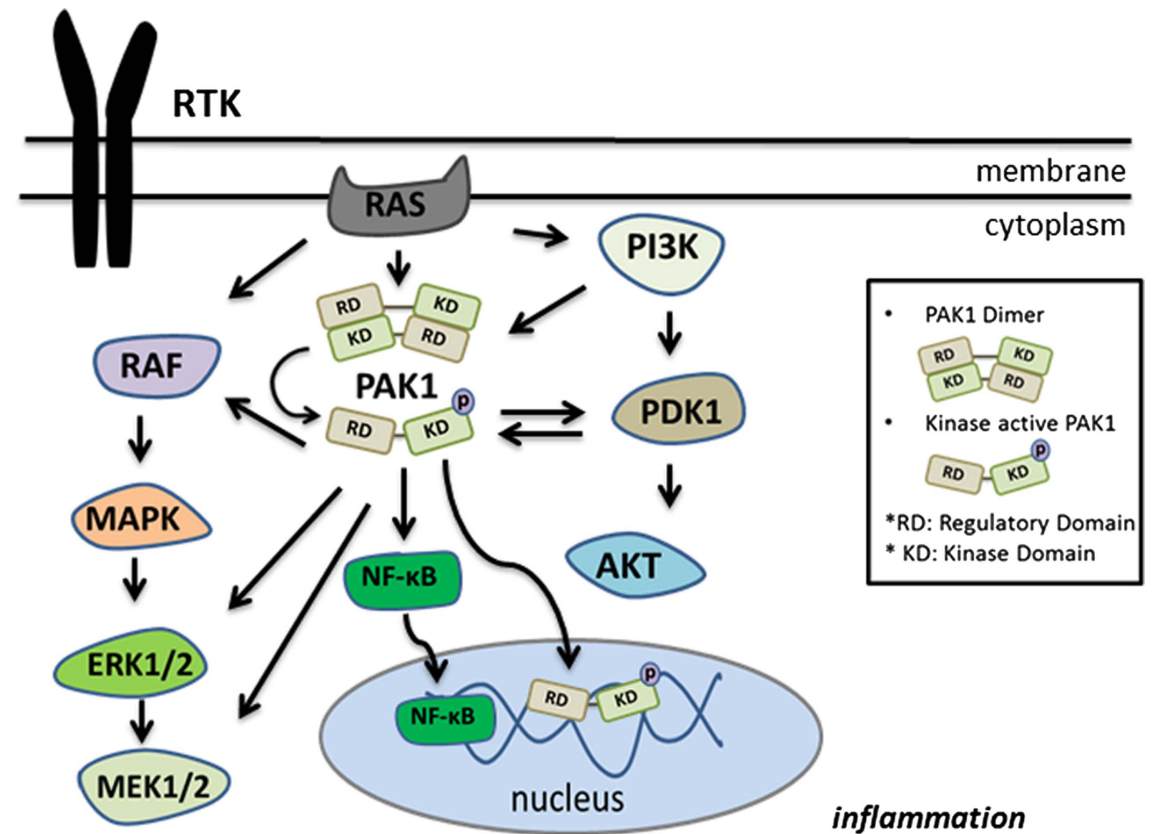

\section{inflammation proliferation survival migration}

or via overexpression of a kinase dead PAK1 mutant (KD-PAK1), inhibited nuclear translocation of RelA. ${ }^{88}$

caspase-1 cleavage to promote maturation of IL-1 $\beta$ in LPS mulated macrophages. ${ }^{87}$ PAK4 is involved in canonical TNF $\alpha /$ $\mathrm{NF}-\kappa \mathrm{B}$ pro-survival signalling in epithelial cells. PAK4 assists TNFR-associated death domain binding to the TNFR1 complex via both kinase and scaffold functions. ${ }^{66}$ Preliminary data indicate that PAK1 plays a critical role in canonical NF- $\mathrm{KB}$ signalling in normal diploid human colon epithelial cells. ${ }^{88}$ TNF $\alpha$ treatment was sufficient to activate PAK1 through phosphorylation at Thr-423. PAK1 activation initiated RelA translocation to the nucleus, and its inhibition via a specific kinase inhibitor, IPA-3,

\section{PAKS IN GI DISEASES}

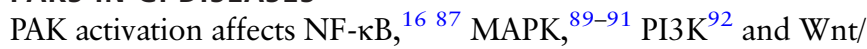
$\beta$-catenin signalling ${ }^{13}$ linking inflammation and malignant transformation in the gut. Further, PAK signalling promotes epithelial-mesenchymal transition and invasiveness, ${ }^{1} 393$ both of which are common features of colitis-associated cancer (CAC). PAK activation has been associated with point mutations and

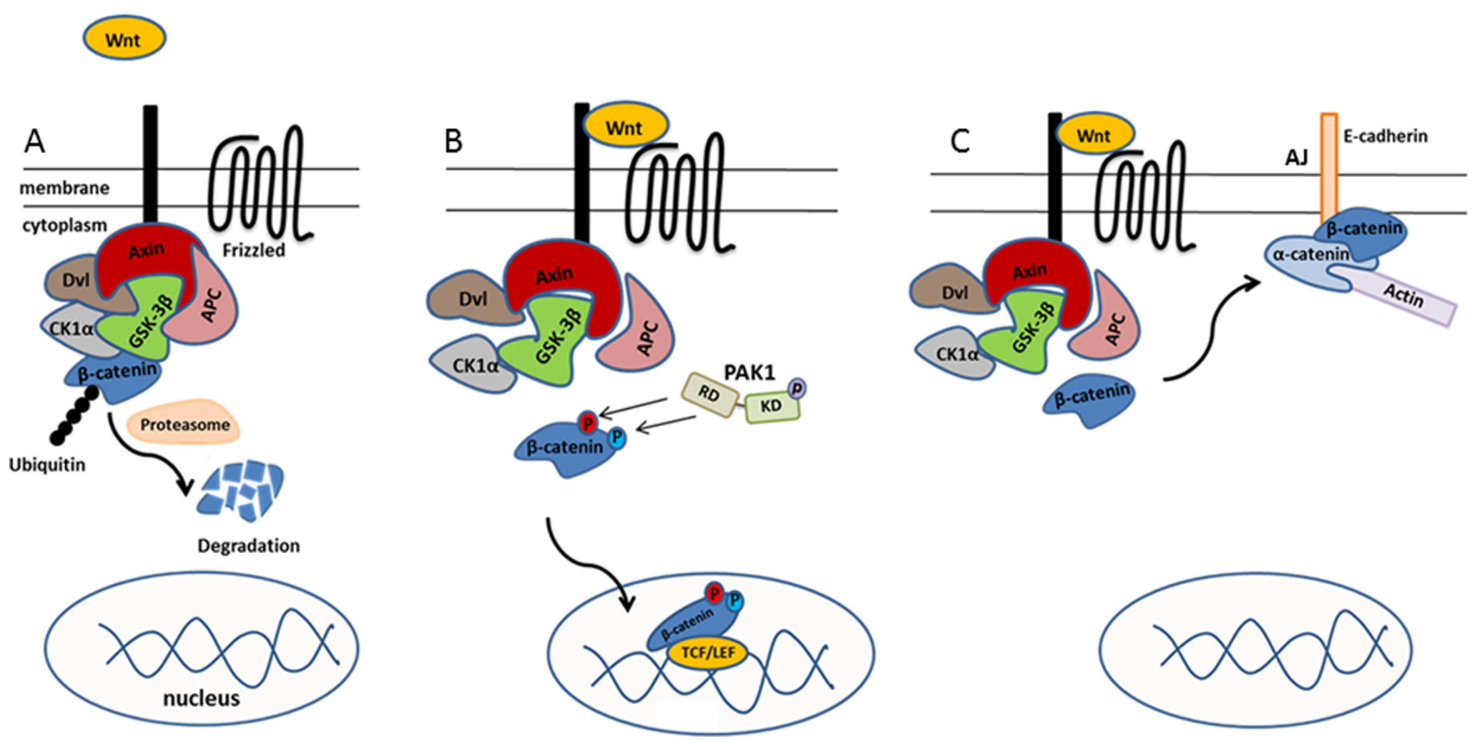

Figure 3 P-21 activated kinase (PAK)1 facilitates Wnt/ $\beta$-catenin signalling. (A) In the absence of the Wnt ligand, $\beta$-catenin signalling is regulated and $\beta$-catenin is degraded through a multiprotein destruction complex. (B) Upon binding of the Wnt ligand to the membrane-bound Frizzled receptor, $\beta$-catenin accumulates in the cytoplasm and translocates to the nucleus. Phosphorylation of $\beta$-catenin by PAK1 within the cytoplasm occurs at two different residues, Ser-663 (red) and Ser-675 (blue), although only Ser-663 is specific to PAK1. As a consequence, $\beta$-catenin stability, nuclear translocation and transcriptional activity are increased. (C) In the absence of PAK1 activity, $\beta$-catenin is restored at adherens junction (AJ) where it anchors E-cadherin to the cytoskeleton through an interaction with $\alpha$-catenin. 

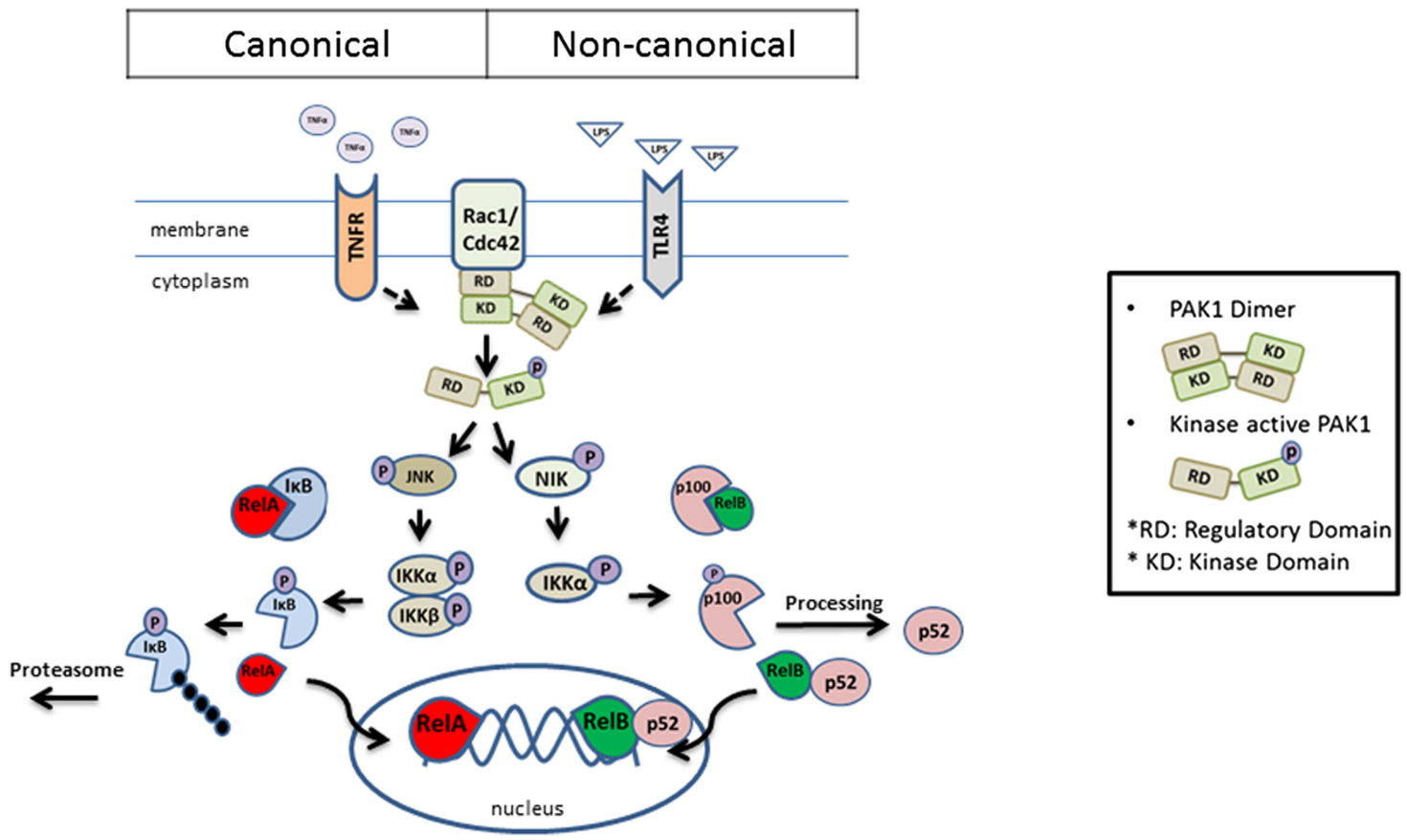

Figure 4 P-21 activated kinase (PAK)1 in canonical and non-canonical NF- $\kappa B$ signalling. NF- $\kappa B$ signalling regulates transcription of target genes via two separate cascades known as the canonical and non-canonical pathways. In the canonical pathway, TNF $\alpha$ elicits PAK1 and c-Jun N-terminal kinase (JNK) phosphorylation. Subsequent phosphorylation of IKK $\alpha / \beta$ by JNK initiates phosphorylation of IKB. Consequently, RelA is released from the $I_{\kappa} B$ complex and translocates into the nucleus. I $\mathrm{K}$ is tagged by ubiquitin for proteasomal degradation. LPS is a known activator of non-canonical NF- $\kappa B$ signalling. LPS may elicit PAK1 activation through an unknown mechanism. PAK1 phosphorylates and activates NF- $\kappa B$ interacting kinase (NIK), which activates IKK $\alpha$. In turn, IKK $\alpha$ phosphorylates $\mathrm{p} 100$ and the p100-RelB complex is released. P100 is processed into p52 which dimerises with RelB and translocates to the nucleus to activate target genes.

subsequent gene amplification, ${ }^{43}$ while mutations in activators upstream of PAK, such as Rac1/Cdc42, may constitutively activate PAKs. ${ }^{2}$ Multiple alterations in PAK signalling were identified in inflammatory bowel diseases and various GI cancers (table 2).

\section{Infectious diarrhoea}

Bacterial enterotoxins use PAK1 as a cellular effector to break intestinal tight junctions (TJ) and impede epithelial barrier. ${ }^{94}$ Enteropathogenic E coli (EPEC), a human intestinal attaching and effacing pathogen, is a major cause of diarrhoea in the developing world. ${ }^{94-96}$ EPEC uses a type-three secretion system to penetrate the epithelial barrier. EPEC injects EPEC-secreted proteins (EspG or EspF) within enterocytes and causes diarrhoea by interfering with intestinal transport and disrupting TJ. EspG inhibits the anion exchanger downregulated-in-adenoma, while EspF downregulates the $\mathrm{Na}^{+} / \mathrm{H}^{+}$exchanger (NHE3) and $\mathrm{Na}^{+}$/glucose transporter (SGLT1) within the gut. ${ }^{94}$ TJ proteins such as claudin-1, ZO-1 and occludin are continually maintained at cell-to-cell contacts through mechanisms which require endocytosis and constant remodelling of the cytoskeleton. Both microtubule disruption and actin depolymerisation impair $\mathrm{TJ}$ thereby disrupting epithelial barrier. ${ }^{94}$ EspG1 and EspG2 disrupt microtubules as well as impairing protein secretion and trafficking from the Golgi apparatus. Both groups I and II PAKs facilitate cytoskeletal rearrangements through modification of actin. Interestingly, EspG1, directly binds PAK2, disrupts the PAK auto-inhibited dimer and activates its kinase activity almost eightfold. ${ }^{31}$ This suggests that EPEC uses host's PAK signalling to induce barrier dysfunction within the gut. ${ }^{97}$

\section{IBD and CAC}

UC is a chronic inflammatory disease of the large bowel. ${ }^{98}$ Even though the pathogenesis of UC is multifactorial and complex, it is widely accepted that chronic inflammation is a precursor to

Table 2 Effect of PAKs on cell signalling cascades in GI disease

\begin{tabular}{|c|c|c|c|c|c|c|c|c|c|c|c|}
\hline \multicolumn{12}{|l|}{ Effect of PAKs on signalling cascades } \\
\hline \multirow[b]{2}{*}{ Disease } & \multicolumn{2}{|c|}{ Wnt/及-catenin } & \multicolumn{2}{|l|}{ MAPK } & \multicolumn{2}{|l|}{ PI3K } & \multicolumn{2}{|l|}{ mTOR } & \multicolumn{2}{|l|}{ NF-кB } & \multirow[b]{2}{*}{ Reference } \\
\hline & PAK1 & PAK4 & PAK1 & PAK4 & PAK1 & PAK4 & PAK1 & PAK4 & PAK1 & PAK4 & \\
\hline IBD & - & - & - & - & - & - & - & - & + & - & 7688105 \\
\hline Colorectal cancer & + & - & + & + & + & + & + & - & - & - & 13145974769192152 \\
\hline Gastric cancer & + & - & + & + & - & + & - & - & + & - & 16130137166 \\
\hline Oesophageal squamous cell carcinoma & - & - & + & - & - & - & - & - & - & - & 145 \\
\hline Hepatocellular carcinoma & - & - & + & - & - & + & - & - & - & - & 1844 \\
\hline
\end{tabular}

(+) investigated; (-) not investigated.

MAPK, mitogen activated protein kinase; PAK, P-21 activated kinase; PI3K, phospoinositide 3-kinase. 


\section{Human}
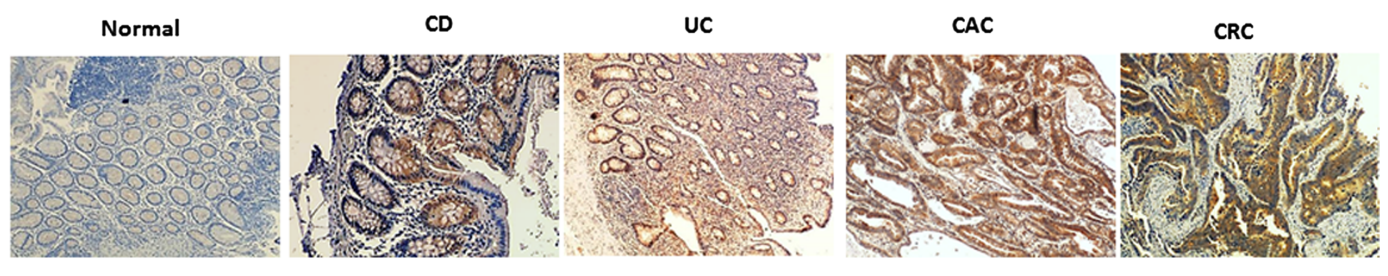

Mouse (C57BL/6)
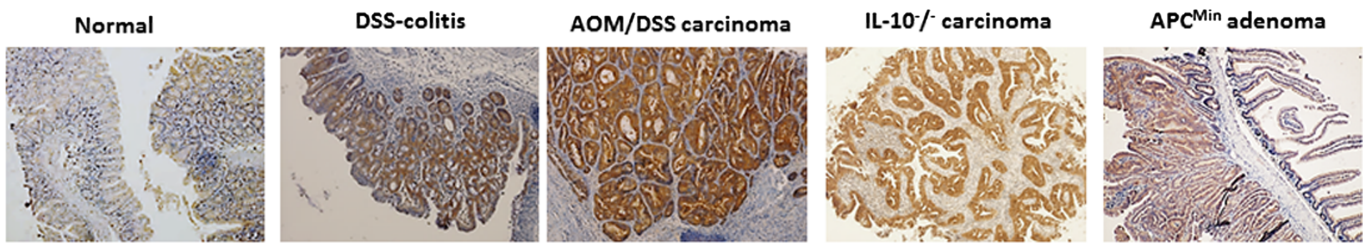

Figure 5 Immunohistochemical expression of P-21 activated kinase (PAK)1 in intestinal inflammation and colorectal cancer. In humans, PAK1 expression is low within normal colon mucosa. Chronic inflammation of the gut as observed in Crohn's disease (CD) and UC increases PAK1 expression. PAK1 is highly expressed in both colitis-associated cancer (CAC) and colorectal cancer (CRC). PAK1 expression was also found to be elevated in an animal model of experimental colitis (DSS-colitis) and AOM/DSS-induced colorectal cancer. IL-10 knockout mice which show spontaneous enterocolitis progressing to CAC also express higher levels of PAK1. APC ${ }^{\mathrm{min}}$ mice also display high PAK1 levels in adenomas.

neoplastic transformation in CAC, ${ }^{99}$ which is multifocal, accelerated and with a mutational sequence that differs from sporadic colorectal carcinoma (CRC). ${ }^{100}$ P53 and RAS mutations have been identified as rather early steps in this process, ${ }^{101}$ and may initiate Rac1, NF-кB, PI3K and MAPK signalling. Alternatively, loss of APC and subsequent activation of nuclear $\beta$-catenin signalling are late events. ${ }^{102}$

PAK1 has been correlated to a variety of inflammatory diseases such as arthritis, asthma as well as intestinal inflammation (figure 5). ${ }^{24}{ }^{103-105}$ One likely driver of PAK1 activation in IBD is TNF $\alpha .{ }^{88}$ PAK1 activation triggers signalling pathways which drive proliferation, initiate cell migration or block apoptosis, and may contribute to a loss of intestinal barrier function. PAK1 expression was higher upon disease progression to CAC. A similar pattern was observed in IL-10 KO mice, a common model for studying CAC. ${ }^{105}$ It is tempting to speculate that PAK1 might be responsible for fuelling various signalling cascades involved in CAC.

The CDH1 locus encoding E-cadherin is one of the barrier function genes implicated in the pathogenesis of UC. ${ }^{106}$ As described above, E-cadherin is important for assembly of AJ. Inhibition of PAK1 expression by mesalamine increased cell-to-cell adhesion through membranous restoration of E-cadherin at AJ. ${ }^{76}$ Therefore, the effect of mesalamine on PAK1 inhibition and restoration of intestinal barrier function may be a critical mechanism of this drug to achieve mucosal healing in UC.

\section{Colorectal cancer}

In comparison with other malignant GI diseases, CRC has the highest incidence and the third highest mortality rate due to cancer worldwide. ${ }^{107}$ Molecular mechanisms of CRC include chromosomal instability, microsatellite instability or the CpG-island methylator phenotype, all of which are also found in CAC. ${ }^{102} 108$ CAC involves DNA damage (double strand breaks and point mutations) likely from reactive oxygen species, and an altered DNA damage response. ${ }^{108}$ Mutations of APC, KRAS, BRAF and p53 drive the adenoma-to-carcinoma sequence in sporadic CRC. ${ }^{109}$ Carter and colleagues were the first to report that PAK1 is overexpressed in CRC studying biopsies from patients with various stages of disease. ${ }^{110}$ Immunohistochemical analysis revealed PAK1 expression was cytoplasmic within the colonic epithelium. Normal epithelial cells had significantly lower PAK1 staining than neoplastic cells, and the expression increased with disease progression. PAK1 staining was highest in lymph node metastases and was associated with decreased patient survival. ${ }^{110} 111$ Other investigations confirmed that both PAK1 and phospho-PAK1 were highly expressed in human and mouse CRC tissue samples ${ }^{105} 111$ (figure 5). Advanced CRC showed nuclear PAK1 expression indicative of poor patient prognosis. ${ }^{91}$ PAK4 mutations have also been identified in CRC; however, evidence is lacking to validate its role as driver of tumourigenesis. ${ }^{2} 43$ A separate study reported that PAK5 expression increased with CRC progression and implicated its role in metastasis. ${ }^{112}$ Considering that PAK1 expression increases throughout the adenoma-to-carcinoma sequence, it is plausible that PAK1 may be used as a biomarker for tumour grading. As multiple PAKs are overexpressed in CRC, future studies should compare the expression patterns between groups I and II PAKs to identify which PAK will serve as a better molecular target.

One important step of early colorectal tumourigenesis comprises the loss of APC function. Constitutive Wnt signalling provides high levels of nuclear $\beta$-catenin to fuel proliferation within stem cells of the crypts. ${ }^{71}$ Loss of APC was shown to induce crypt proliferation and activate Rac1, while epithelial-specific deletion of both APC and Rac1 reduced crypt proliferation specifically through repression of the $\mathrm{LGR}^{+}$population. ${ }^{77}$ Inhibition of Rac1 also impedes RAS-driven proliferation. ${ }^{77}$ PAK1 as a key effector of Rac1 is expected to be activated upon loss of APC as well, which may cause amplification of $\beta$-catenin's transcriptional activity. A functional relation between PAK1 and $\beta$-catenin has been established by inhibiting PAK1 in tumour cells: small interfering RNA (siPAK1) and KD-PAK1 significantly reduced $\beta$-catenin and cyclin D1 at the protein level. ${ }^{13}$ Moreover, PAK1 and $\beta$-catenin were found to be associated together in the cytoplasm. ${ }^{13} 113$ The functional significance of this protein interaction was shown by direct phosphorylation of 
$\beta$-catenin by PAK1. ${ }^{13}$ Activated PAK1 phosphorylates the C-terminus of $\beta$-catenin at Ser- $675 .^{13}$ It is important to note that $\beta$-catenin's Ser-675 domain is not exclusive to PAK1 since PAK4 ${ }^{114}$ and $\mathrm{PKA}^{115}$ also phosphorylate the same residue. Instead, Ser-663 is an exclusive target of PAK1. ${ }^{74}$ The consequence of multiple phosphorylation sites increases $\beta$-catenin stability, as well as transcriptional activation of Wnt target genes. Both sites were phosphorylated in CRC tumours and cell lines. Inhibition of PAK1 with IPA-3, a PAK1 kinase inhibitor, specifically reduced Ser-663 whereas a PI3K inhibitor (LY294002) and a PKA inhibitor (H-89) had no such effects. ${ }^{74}$ These findings established that PAK1 plays a direct role in the activation of Wnt/ $\beta$-catenin signalling in colonic epithelial cells.

RAS and RAF mutations lead to MAPK and PI3K pathway activation, and contribute to the adenoma-to-carcinoma sequence in CRC. ${ }^{90}{ }^{116-118}$ Inhibition of both PAK1 and PAK4 blocks RAS-mediated cell proliferation and survival. ${ }^{14}$ RAS mutations hyperactivate PAK1 and initiate PAK1/ERK or PAK1/ PI3K cascades. $^{92}$ PAK1 knockdown reduced proliferation and survival, although pharmacological inhibition of ERK or PI3K alone could not. Interestingly, inhibition of PAK1 and ERK or PI3K lacked synergism, ${ }^{92}$ and this line of evidence suggested the crosstalk of ERK/PI3K observed upon mutated RAS or PI3K pathways can be effectively inhibited by blocking PAK1 in CRC.

Various studies provide insight concerning PAK1's role within CRC establishing that PAK1 activation promotes an invasive phenotype. ${ }^{92}$ PAK1 activation was shown to activate signalling cascades which contribute to invasiveness such as the MAPK and PI3K cascades. ${ }^{92}$ Interestingly, it was shown that PAK1 knockdown inhibited both PI3K and MAPK signalling thereby blocking the secretion of vascular endothelial growth factor (VEGF), an important mediator of tumour angiogenesis and cell survival. ${ }^{92}$ Another potential mechanism of VEGF activation includes a PAK1-HIF1 $\alpha$ cascade. ${ }^{119}$ Specific inhibition of PAK1 kinase activity reduced colony formation in HCT116 and SW480 cells, and KD-PAK1 initiated G1 arrest in SW480 cells. ${ }^{13}$ LoVo cells transfected with shPAK1 also induced a G1 arrest via downregulation of CDK4/6 and cyclin D1. PAK1 knockdown increased apoptosis and was correlated to reduction in phospho-BAD, Bcl-2, Bcl-xL and XIAP proteins. ${ }^{91}$

To better understand how PAK1 contributes to ERK-mediated cell migration and tumour invasion, the regulation of focal adhesion contacts via ERK phosphorylation of FAK at Ser-910 was studied. ${ }^{111}$ PAK1 overexpression increased FAK Ser-910 phosphorylation, whereas both KD-PAK1 and siPAK1 had inhibitory effects. Activation of PAK1 via EGF stimulated phosphorylation of PAK1, ERK and FAK. Downregulation of MEK1/ 2 with a pharmacological inhibitor, U0126, reduced the migration and invasion of HCT116 and SW116 cells; however, a more potent reduction in migration was observed using siPAK1. These observations imply that targeting PAK1 is a viable option to decrease the migration and invasion of tumour cells. ${ }^{111}$

In conclusion, PAK overexpression is associated with increased cell proliferation and migration thereby promoting invasion and inhibition of apoptosis in CRC. The effect of PAK1 overexpression in normal colon epithelium remains to be investigated in order to explain if activation of oncogenic signalling promotes PAK1 activity or PAK1 itself contributes to neoplastic progression.

\section{Peutz-Jeghers syndrome}

Hereditary intestinal polyposis or Peutz-Jeghers syndrome (PJS) is characterised by the development of hamartomatous GI polyps and predisposes to cancer susceptibility. Germline mutations in the tumour suppressor gene LKB1 have been linked to this syndrome. ${ }^{120}$ LKB1 is downstream of p53 and may regulate PAK1 activity. Suppression of PAK1 by LKB1 is mediated by its phosphorylation at Thr-109, ${ }^{121}$ suggesting the role of LKB1 in suppression of cell migration through inhibition of PAK1. LKB1 regulates cellular responses by AMPK/mTOR signalling, which is reflected in PJS lesions that are associated with mTOR hyperactivation. ${ }^{122}$ With recent evidence indicating the role of PAK1 in mTOR signalling, ${ }^{123}$ it is imperative to investigate PAK1 expression in PJS polyps as well as PAK1's role in the activation of $\mathrm{mTOR}$ in this disease.

\section{PAK1 and gastrin}

GI peptide hormones, such as gastrin, play fundamental roles in gastric acid secretion, ${ }^{124}$ as well as increasing cell transformation, ${ }^{125}$ proliferation ${ }^{126}$ and evasion of apoptosis ${ }^{127}$ within GI cancer. $^{128} 129$ Gastrin is post-translationally modified into amidated gastrin (Gamide) and glycine extended gastrin (Gly-gastrin). Gastrin $\mathrm{KO}$ mice display marked reduction in expression of total and phosphorylated PAK1 within the colorectal mucosa, ${ }^{63}$ and both Gamide and Gly-gastrin increased Rho GTPase activity and increased the phosphorylation status of PAK1 within a transgenic mouse gastric mucosal cell line. ${ }^{128} 130131$

He et $a l^{128}$ investigated PAK1's relationship to the Wnt/ $\beta$-catenin pathway and established that PAK1 regulates $\beta$-catenin activity downstream of gastrins. PAK1 and $\beta$-catenin's interaction was revealed by immunoprecipitation, while immunostaining confirmed their colocalisation. Treatment with gastrins stimulated migration of the complex to the nucleus; however, $\beta$-catenin remained membranous upon treatment with both the KD-PAK1 mutant and transient silencing of PAK1 (siPAK1). ${ }^{128}$ Treatment with gastrins reduced the association of $\beta$-catenin with E-cadherin; however, KD-PAK1 abrogated this effect. ${ }^{128}$ These observations indicated the role of PAK1 in the nuclear translocation of $\beta$-catenin. Gastrin treatment stabilised nuclear $\beta$-catenin, increased the association with the transcription factor TCF4, and increased the transcription of c-myc and cyclin D1; however, transfection with KD-PAK1 inhibited this effect. ${ }^{128}$ Gastrins stimulated migration within a wound-healing assay, and KD-PAK1 abolished this effect. This study established a novel role of PAK1 in the activation of $\mathrm{Wnt} / \beta$-catenin signalling downstream of gastrins.

\section{Helicobacter pylori and GC}

Helicobacter pylori infection is implicated in chronic gastritis, duodenal ulcer, gastric metaplasia, gastric MALT lymphoma and gastric cancer (GC). ${ }^{132}$ Activation of Rho GTPases Rac1/Cdc42 by $H$ pylori lead to PAK1-mediated nuclear responses, representing an early event in epithelial colonisation by this strain. ${ }^{133}$ Moreover, activation of the NF- $\mathrm{BB}$ pro-inflammatory pathway by $H$ pylori involved direct interaction of PAK1 and NIK. ${ }^{86}$

Worldwide GC has the fourth highest cancer-associated mortality rate. ${ }^{134}$ Early GC is asymptomatic, and difficult to identify by endoscopy. Thus, patients are often diagnosed at late tumour stage and with a poor survival. ${ }^{134}$ PAK mRNA and protein expression were found to be upregulated in GC cancer cells. $^{135} 136$ PAK4 and PAK1 were correlated with increased tumour growth, invasion, metastasis and poor prognosis in GC patients. $^{16}{ }^{136-138}$ Dysregulation of transcription growth factor- $\beta$ (TGF- $\beta$ ) signalling plays a key role in GI inflammation and cancer. ${ }^{139}$ TGF- $\beta$ transmits signals to the nucleus via a network of multiprotein complexes using the SMA and mothers against decapentaplegic (MAD; SMAD) family of proteins. Loss of SMAD was correlated to GC susceptibility, ${ }^{140}$ and HGF 
activation of PAK4 induced SMAD2 phosphorylation and proteasomal degradation. ${ }^{17}$ One mechanism in which PAK4 may promote GC metastasis is through the modification of microtubule homeostasis proteins such as superior cervical ganglia 10 (SCG10). PAK4 phosphorylates SCG10 and initiates cell migration and invasion in vivo. ${ }^{141}$

PAK1 knockdown in a GC xenograft model reduced tumour size. ${ }^{16}$ Stable and transient knockdown of PAK1 within GC cell lines (BGC823 and ACS) induced G2 cell cycle arrest, reduced proliferation and inhibited anchorage independent cell growth. ${ }^{16}$ Overexpression of the catalytically active (CA-PAK1) mutant enhanced the expression of cyclin B1, a critical component of the G2/M transition of the cell cycle, whereas PAK1 inhibition decreased the transcription of cyclin B1. PAK1 defi-

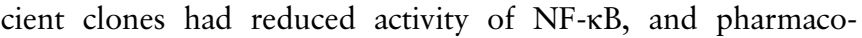
logical inhibition of $\mathrm{NF}-\kappa \mathrm{B}$ reduced the activity of cyclin B1. Interference with $\mathrm{NF}-\kappa \mathrm{B}$ activity, through a mutant $\mathrm{I} \kappa \mathrm{B} \alpha$ vector, interfered with CA-PAK1-induced upregulation of cyclin B1. Liu et $a l^{16}$ concluded that overexpression of PAK1 in GC may regulate proliferation through an increase in cyclin B1 via $\mathrm{NF}-\kappa \mathrm{B}$. A recent report suggested that PAK1 overexpression in GC activates the ERK and c-Jun N-terminal kinase (JNK) pathways, thereby playing a role in the metastatic phenotype. ${ }^{137}$ These studies implicate both PAK1 and PAK4 in GC. PAK4 modification of SMAD in the TGF $\beta$ pathway and PAK1's role within the NF- $\kappa \mathrm{B}$, ERK and JNK pathways contribute to proliferation, invasion and metastasis of GC.

\section{Hepatocellular carcinoma}

Similar to CRC, overexpression of PAK1 in hepatocellular carcinoma (HCC) is associated with advanced tumour stages. A recent report by Wong and colleagues demonstrated that PAK1 activates NF- $\mathrm{BB}$ in HCC cells and IPA-3 abrogated this effect. Within a HCC xenograft model, IPA-3 treatment significantly reduced tumour volume, and also inhibited phosphorylation of PAK1 and JNK. ${ }^{142}$ Increased cell motility and migration was observed in HCC cell lines stably expressing PAK1. Cell lines with higher expression of PAK1 showed JNK activation and inhibition of JNK reduced migration in HCC cells. ${ }^{18}$ Activation of VEGFR2/PAK1 signalling was found to promote resistance to anoikis in hepatoma patients with high expression of Klotho, an ageing suppressor gene. ${ }^{143}$ Inhibition of PAK1 activity by shRNA or IPA-3 reversed this effect in hepatoma cells. PAK1 is also upregulated by $\mathrm{HBV}$ protein $\mathrm{HBx}$ that renders hepatoma cells resistant to anoikis. ${ }^{144}$

\section{Oesophageal cancer}

Oesophageal squamous cell carcinoma (OSCC) is marked by poor prognosis, and has increasing prevalence in eastern society. ${ }^{107} 145$ In order to identify genetic changes within oesophageal tumour cells, one study used an ESCC xenograft model. ${ }^{15} 146$ Lymph fluid collected from patients with ESCC was injected into nude mice, and analysed via array based comparative genomic hybridisation. Interestingly, the authors identified PAK1, which increased fivefold during tumour growth. ${ }^{15}$

The MAPK pathway was investigated in ESCC cancer cell lines derived from bone marrow metastasis in ESCC patients. Overexpression of the ERK pathway was found to be independent of MEK1/2 $2^{145}$ as pharmacological inhibitors of MEK1 (PD98059), MEK1/2 (U0126) and dominant negative DN-MEK1/2 failed to abolish ERK activity. ${ }^{145}$ However, pharmacological inhibition of the PI3K pathway using LY294002 or overexpression of KD-PAK1 DN-PAK1 mutants clearly reduced ERK activity. ${ }^{145}$ Although the PAK1 mutants did not affect total protein levels of ERK1/2 or alter the JNK pathway, this report demonstrated that interplay of PI3K and PAK1 stimulated ERK pathway independently of MEK. Continual crosstalk among multiple cell signalling cascades in ESCC may present a challenge in therapeutic inhibition of MAPK signalling. However, targeting PAK1 in ESCC may present an opportunity to inhibit cell signalling interplay thereby increasing the specificity of pharmacological ERK inhibition.

\section{PHARMACEUTICAL MODULATION OF PAK1}

Through its participation in multiple signalling pathways, PAK1 overexpression in GI cancer promotes cell proliferation, survival and metastatic progression evading apoptosis (table 3 ).

Considering the contribution of PAK1 to GI disease, future strategies aim to target PAK1 expression or inhibition of its kinase activity for prevention or treatment.

\section{Inhibition of PAK expression}

In a microarray analysis performed to examine molecular targets of mesalamine, PAK1 was identified as a common mediator of pathways modulated in colorectal epithelial cells. ${ }^{76}$ In vivo, PAK1 was overexpressed in intestinal polyps of $\mathrm{APC}^{\mathrm{min}}$ mice, and mesalamine blocked both PAK1 expression and tumour progression. ${ }^{76}$ In vitro, mesalamine blocked PAK1 at the protein level. ${ }^{76}$ As outlined above, PAK1 expression is elevated in gut inflammation ${ }^{105}$ and plays a role in the activation of the NF- $\kappa$ B pro-inflammatory pathway. ${ }^{88}$ Inhibition of PAK1 and subsequent NF- $\mathrm{B}$ downregulation by mesalamine may be one mechanism in which mesalamine blocks inflammation and CAC altered innate immunity such as activated neutrophils-induced cell stress. ${ }^{147}$ PAK1 is required for degranulation ${ }^{148}$ of mast cells and neutrophil activation. ${ }^{149}$ Downregulation of PAK1 by

Table 3 P-21 activated kinase (PAK) overexpression in GI tumourigenesis

\begin{tabular}{|c|c|c|c|c|c|c|c|}
\hline \multirow[b]{2}{*}{ Disease } & \multicolumn{2}{|c|}{ Proliferation } & \multicolumn{2}{|c|}{ Invasion } & \multicolumn{2}{|c|}{ Metastasis } & \multirow[b]{2}{*}{ Reference } \\
\hline & PAK1 & РАK4 & PAK1 & PAK4 & PAK1 & PAK4 & \\
\hline Colorectal cancer* & + & + & + & + & + & - & 14749192110111113 \\
\hline Gastric cancer ${ }^{*}$ & + & - & + & - & + & + & 1686 134-138 141 \\
\hline Oesophageal squamous cell carcinoma* & - & - & - & - & + & - & 15145 \\
\hline Hepatocellular carcinoma* & + & - & + & - & - & - & 18143144 \\
\hline
\end{tabular}


mesalamine within innate immune cells may provide an effective therapeutic approach in reducing inflammation in active UC.

Another approach to inhibit expression of PAK1 involves overexpression of miRNA-29, which negatively regulates the cdc42 and PI3K pathways. ${ }^{150}$ MiRNA-29 inhibited PAK1 at the protein level, reduced proliferation, migration and cell invasion in GC cells. ${ }^{151}$ MiRNA-145 was shown to target PAK4 and impedes cell growth in CRC cells. ${ }^{152}$ Although, future studies are required to understand if miRNA-29 or 145 can be used to pharmacologically modulate PAK expression in vivo.

Bradykinin, which is known to be overexpressed in cancer, is implicated in angiogenesis. ${ }^{153}$ Furthermore, PAK1 has been correlated to angiogenesis ${ }^{154}$ and is a known effector of the bradykinin pathway. ${ }^{155}$ It was shown that overexpression of the IRX1 gene significantly downregulated both bradykinin and PAK1 protein levels in GC cells. ${ }^{155}$ It is noteworthy that the IRX1 gene was identified as a tumour suppressor gene in $\mathrm{GC}^{156} 157$ and restoration of IRX1 in vitro and in vivo reduced the metastasis of GC cells. ${ }^{155}$ Prospective studies should investigate if pharmacological modulation of IRX1 is effective in blocking angiogenesis and PAK1 within other GI diseases.

The complexity of targeting PAK1 is highlighted by the fact that PAK1 has a plethora of kinase dependent and independent cellular functions. Therefore, inhibition of total PAK1 expression may be an effective approach in PAK1 intervention. Future studies should identify whether downregulation of PAK1 expression by mesalamine, miRNA- 29 or modulation of IRX1 is more effective in blocking inflammation than inhibition of PAK1 kinase activity alone.

\section{PAK1 kinase inhibition}

The Rho GTPase Rac1 plays a key role in PAK1 kinase activation, ${ }^{29}$ as well as $\mathrm{T}$ cell proliferation and differentiation. ${ }^{158}$ Tiede et al reported that azathioprine and 6-mercaptopurine (6-MP) induced apoptosis in activated CD4 $\mathrm{T}$ cells through inhibition of Rac1. Rac1 inhibition blocked downstream prosurvival signalling via downregulation of NF-KB, MAPK and bcl-xL. ${ }^{159}$ Considering that PAK1 mediates all three of these pathways, it is important to investigate the effect of azathioprine and 6-MP on PAK1 kinase activation and downstream signalling within both inflammatory and epithelial cells.

\section{Synergistic effects with 5-FU}

In CRC, 5-flurouracil (5-FU) is a mainstay chemotherapeutic drug; however, its effectiveness is limited due to drug resistance. ${ }^{160}$ Therefore, it is of great interest to investigate a possible synergism in PAK1 inhibition and 5-FU. Interestingly, in vitro, knockdown of PAK1 increased apoptosis in 5-FU treated LoVo cells. ${ }^{91}$ Additionally, it was investigated if PAK1 knockdown and 5 -FU synergistically inhibits tumour growth in a xenograft model. LoVo cells harbouring shPAK1 constructs were injected into nude mice and PAK1 knockdown significantly reduced tumour growth and proliferation. ${ }^{91} \mathrm{~A}$ further reduction in tumour growth was observed in combination with 5 -FU.

\section{Small molecule PAK1 inhibitors}

Analysis of PAK1's crystal structure has allowed for the identification and design of several PAK1 inhibitors. ${ }^{29}$ Initial studies analysed complexes of non-specific ATP-competitive inhibitors, such as staurosporine derivatives, with PAK1 to conceptualise kinase inhibition. ${ }^{161}$ However, identifying a selective inhibitor for PAK1's ATP binding pocket has proved to be difficult. Initially, CEP-1347 was found to inhibit PAK1 but further studies revealed its higher affinity for mixed lineage kinase-3 than PAK1 itself. ${ }^{162}$ The celecoxib derivative OSU-03012 was originally identified as a PDK1 inhibitor. Interestingly, it was found to inhibit group I PAKs although not completely specific to PAK1. ${ }^{163}$ At present, the most potent and selective ATP-competitive inhibitor of PAK1 is the organouthenium compound FL172, which has been shown to be effective within the nanomolar range, respectively. ${ }^{162}{ }^{164}$ Recently identified PAK1 ATP inhibitors include 2-arylamino-4-aryl-pyrimidines. ${ }^{165}$ These selective compounds blocked proliferation of multiple CRC cell lines at nanomolar concentrations, and their non-cytotoxicity provides a rational to investigate their effectiveness in vivo. ${ }^{165}$

Although ATP inhibitors are thought to be highly potent, they are often non-specific. ${ }^{162}$ Alternatively, allosteric inhibition of PAK1 would be less potent, but more specific. IPA-3 is an allosteric small molecule inhibitor of PAK1. It blocks PAK1 kinase activation by covalently binding to the PBD and inhibiting activation by Rac1/Cdc42. However, IPA-3 cannot inhibit PAK1 which is already activated. ${ }^{162}$ IPA-3 is widely used in cell culture, although its efficiency in animal models may be limited due to a disulfide bond within the molecular structure. ${ }^{3}$ Nevertheless, IPA-3 has served as a platform to design allosteric inhibitors which have increased selectivity and therapeutic effectiveness within in vivo systems.

\section{FUTURE DIRECTIONS}

With accumulating evidence establishing the role of PAK1 in GI inflammation and CRC, it is reasonable to examine the effect of PAK1 inhibitors in disease prevention and therapy. However, considering that PAK1 orchestrates multiple signalling cascades, it is important to understand the underlying cause of PAK1 overexpression in order to target this molecule. Future studies are requisite to validate PAK1 as a biomarker and pharmaceutical target.

Acknowledgements The financial support by the Federal Ministry of Economy, Family and Youth and the National Foundation for Research, Technology and Development is gratefully acknowledged.

Funding The study was supported by Austrian Science Fund (P24121 to Christoph Gasche).

Competing interests CG has a research collaboration with Shire Pharmaceuticals and received research support, lecturing or consulting honoraria from Ferring and $\mathrm{Dr}$ Falk Pharma.

Provenance and peer review Commissioned; externally peer reviewed.

Open Access This is an Open Access article distributed in accordance with the Creative Commons Attribution Non Commercial (CC BY-NC 3.0) license, which permits others to distribute, remix, adapt, build upon this work non-commercially, and license their derivative works on different terms, provided the original work is properly cited and the use is non-commercial. See: http://creativecommons.org/ licenses/by-nc/3.0/

\section{REFERENCES}

1 Kumar R, Gururaj AE, Barnes CJ. p21-activated kinases in cancer. Nat Rev Cancer 2006;6:459-71.

2 Radu M, Semenova G, Kosoff $R$, et al. PAK signalling during the development and progression of cancer. Nat Rev Cancer 2014;14:13-25.

3 Eswaran J, Li DQ, Shah A, et al. Molecular pathways: targeting p21-activated kinase 1 signaling in cancer--opportunities, challenges, and limitations. Clin Cancer Res 2012;18:3743-9.

4 Brown JL, Stowers L, Baer M, et al. Human Ste20 homologue hPAK1 links GTPases to the JNK MAP kinase pathway. Curr Biol 1996;6:598-605.

5 Manser $E$, Leung $T$, Salihuddin $H$, et al. A brain serine/threonine protein kinase activated by Cdc42 and Rac1. Nature 1994;367:40-6.

6 Harden N, Lee J, Loh HY, et al. A Drosophila homolog of the Rac- and Cdc42-activated serine/threonine kinase PAK is a potential focal adhesion and focal complex protein that colocalizes with dynamic actin structures. Mol Cell Biol 1996;16:1896-908. 
7 Pavey S, Zuidervaart W, van Nieuwpoort F, et al. Increased p21-activated kinase-1 expression is associated with invasive potential in uveal melanoma. Melanoma Res 2006;16:285-96.

8 Singhal R, Kandel ES. The response to PAK1 inhibitor IPA3 distinguishes between cancer cells with mutations in BRAF and Ras oncogenes. Oncotarget 2012;3:700-8

9 Maruta H. Effective neurofibromatosis therapeutics blocking the oncogenic kinase PAK1. Drug Discov Ther 2011;5:266-78.

10 Shrestha Y, Schafer EJ, Boehm JS, et al. PAK1 is a breast cancer oncogene that coordinately activates MAPK and MET signaling. Oncogene 2012;31:3397-408.

11 Wong $L E$, Chen N, Karantza V , et al. The Pak4 protein kinase is required for oncogenic transformation of MDA-MB-231 breast cancer cells. Oncogenesis 2013;2:e50.

$12 \mathrm{Kim} \mathrm{SR}$, Kim SH, Lee HW, et al. Increased expression of p21-activated kinase in adenomyosis. Fertil Steril 2010;94:1125-8.

13 Zhu G, Wang Y, Huang B, et al. A Rac1/PAK1 cascade controls beta-catenin activation in colon cancer cells. Oncogene 2012;31:1001-12.

14 Tabusa H, Brooks T, Massey AJ. Knockdown of PAK4 or PAK1 inhibits the proliferation of mutant KRAS colon cancer cells independently of RAF/MEK/ERK and PI3K/AKT signaling. Mol Cancer Res 2013;11:109-21.

$15 \mathrm{Kim}$ DH, Muto M, Kuwahara Y, et al. Array-based comparative genomic hybridization of circulating esophageal tumor cells. Oncol Rep 2006;16:1053-9.

16 Liu F, Li X, Wang C, et al. Downregulation of p21-activated kinase-1 inhibits the growth of gastric cancer cells involving cyclin B1. Int J Cancer 2009;125:2511-19.

17 Wang $\mathrm{C}$, Li Y, Zhang $\mathrm{H}$, et al. Oncogenic PAK4 regulates Smad2/3 axis involving gastric tumorigenesis. Oncogene 2013:1-12.

18 Ching $Y P$, Leong VY, Lee MF, et al. P21-activated protein kinase is overexpressed in hepatocellular carcinoma and enhances cancer metastasis involving c-Jun $\mathrm{NH2}$-terminal kinase activation and paxillin phosphorylation. Cancer Res 2007:67:3601-8

19 Rettig M, Trinidad K, Pezeshkpour G, et al. PAK1 Kinase Promotes Cell Motility and Invasiveness through CRK-II Serine Phosphorylation in Non-Small Cell Lung Cancer Cells. PLoS One 2012;7:e42012.

20 Hashimoto H, Sudo T, Maruta H, et al. The direct PAK1 inhibitor, TAT-PAK18, blocks preferentially the growth of human ovarian cancer cell lines in which PAK1 is abnormally activated by autophosphorylation at Thr 423. Drug Discov Ther 2010:4:1-4.

21 Goc A, Al-Azayzih A, Abdalla M, et al. P21 activated kinase-1 (Pak1) promotes prostate tumor growth and microinvasion via inhibition of transforming growth factor $\beta$ expression and enhanced matrix metalloproteinase 9 secretion. J Biol Chem 2013:288:3025-35.

22 Wells $C M$, Whale AD, Parsons $M$, et al. PAK4: a pluripotent kinase that regulates prostate cancer cell adhesion. J Cell Sci 2010;123:1663-73.

23 McCarty SK, Saji M, Zhang X, et al. Group I p21-activated kinases regulate thyroid cancer cell migration and are overexpressed and activated in thyroid cancer invasion. Endocr Relat Cancer 2010;17:989-99.

24 Fu D, Yang $Y$, Xiao $Y$, et al. Role of $p 21$-activated kinase 1 in regulating the migration and invasion of fibroblast-like synoviocytes from rheumatoid arthritis patients. Rheumatology (Oxford) 2012;51:1170-80.

25 McFawn PK, Shen L, Vincent SG, et al. Calcium-independent contraction and sensitization of airway smooth muscle by p21-activated protein kinase. Am J Physiol Lung Cell MolPhysiol 2003;284:L863-L70.

26 Flicek P, Ahmed I, Amode MR, et al. Ensembl 2013. Nucleic Acids Res 2013;41: D48-55.

27 Stepanova D, Chernoff J. PAK1 (p21/Cdc42/Rac1-activated kinase 1 (STE20 homolog, yeast)). Atlas Genet Cytogenet Oncol Haematol 2008:12:318-19.

28 de la Torre-Ubieta L, Gaudilliere B, Yang Y, et al. A FOXO-Pak1 transcriptional pathway controls neuronal polarity. Genes and Dev 2010;24:799-813.

29 Parrini MC, Lei M, Harrison SC, et al. Pak1 kinase homodimers are autoinhibited in trans and dissociated upon activation by $\mathrm{Cdc} 42$ and Rac1. Mol Cell 2002:9:73-83.

30 Baskaran $\mathrm{Y}, \mathrm{Ng} \mathrm{YW}$, Selamat W, et al. Group I and II mammalian PAKs have different modes of activation by Cdc42. EMBO Rep 2012;13:653-9.

31 Selyunin AS, Sutton SE, Weigele BA, et al. The assembly of a GTPasekinase signalling complex by a bacterial catalytic scaffold. Nature 2011;469:107-11.

32 Selyunin AS, Alto NM. Activation of PAK by a bacterial type III effector EspG reveals alternative mechanisms of GTPase pathway regulation. Small GTPases 2011:2:217-21.

33 Tao W, Pennica $D$, Xu L, et al. Wrch-1, a novel member of the Rho gene family that is regulated by Wnt-1. Genes Dev 2001;15:1796-807.

34 Arias-Romero LE, Chernoff J. A tale of two Paks. Biol Cell 2008;100:97-108.

35 Abo A, Qu J, Cammarano MS, et al. PAK4, a novel effector for $\mathrm{Cdc} 42 \mathrm{Hs}$, is implicated in the reorganization of the actin cytoskeleton and in the formation of filopodia. EMBO J 1998;17:6527-40.

36 Strochlic TI, Viaud J, Rennefahrt UE, et al. Phosphoinositides are essential coactivators for p21-activated kinase 1. Mol Cell 2010;40:493-500.

37 King CC, Gardiner EM, Zenke FT, et al. p21-activated kinase (PAK1) is phosphorylated and activated by 3-phosphoinositide-dependent kinase-1 (PDK1). J Biol Chem 2000:275:41201-9.
38 Puto LA, Pestonjamasp K, King CC, et al. p21-activated kinase 1 (PAK1) interacts with the Grb2 adapter protein to couple to growth factor signaling. J Biol Chem 2003:278:9388-93.

39 Daniels RH, Zenke FT, Bokoch GM. alphaPix stimulates p21-activated kinase activity through exchange factor-dependent and -independent mechanisms. J Biol Chem 1999;274:6047-50.

40 Lu W, Mayer BJ. Mechanism of activation of Pak1 kinase by membrane localization. Oncogene 1999;18:797-806.

41 Tao J, Oladimeji P, Rider L, et al. PAK1-Nck regulates cyclin D1 promoter activity in response to prolactin. Mol Endocrinol 2011:25:1565-78.

42 Shin YJ, Kim YB, Kim JH. Protein kinase CK2 phosphorylates and activates p21-activated kinase 1 (PAK1). Mol Biol Cell 2013:24:2990-9.

43 Parsons DW, Wang TL, Samuels Y, et al. Colorectal cancer: mutations in a signalling pathway. Nature 2005:436:792.

44 Wells CM, Abo A, Ridley AJ. PAK4 is activated via PI3K in HGF-stimulated epithelial cells. J Cell Sci 2002;115:3947-56.

45 Li Z, Lock JG, Olofsson H, et al. Integrin-mediated cell attachment induces a PAK4-dependent feedback loop regulating cell adhesion through modified integrin alpha v beta 5 clustering and turnover. Mol Biol Cell 2010;21: 3317-29.

46 Zhang H, Li Z, Viklund EK, et al. P21-activated kinase 4 interacts with integrin alpha $v$ beta 5 and regulates alpha v beta 5 -mediated cell migration. J Cell Biol 2002;158:1287-97.

47 Bokoch GM. Biology of the p21-activated kinases. Annu Rev Biochem 2003:72:743-81.

48 Kichina JV, Goc A, Al-Husein B, et al. PAK1 as a therapeutic target. Expert Opin Ther Targets 2010;14:703-25.

49 Frost JA, Khokhlatchev A, Stippec S, et al. Differential effects of PAK1-activating mutations reveal activity-dependent and -independent effects on cytoskeletal regulation. J Biol Chem 1998;273:28191-8.

50 Qu J, Cammarano MS, Shi Q, et al. Activated PAK4 regulates cell adhesion and anchorage-independent growth. Mol Cell Biol 2001;21:3523-33.

51 llic D, Furuta Y, Kanazawa S, et al. Reduced cell motility and enhanced focal adhesion contact formation in cells from FAK-deficient mice. Nature 1995;377:539-44

52 Delorme-Walker VD, Peterson JR, Chernoff J, et al. Pak1 regulates focal adhesion strength, myosin IIA distribution, and actin dynamics to optimize cell migration. J Cell Biol 2011:193:1289-303.

53 Zegers MM, Forget MA, Chernoff J, et al. Pak1 and PIX regulate contact inhibition during epithelial wound healing. EMBO I 2003;22:4155-65.

54 Liu F, Jia L, Thompson-Baine AM, et al. Cadherins and Pak1 control contact inhibition of proliferation by Pak1-betaPIX-GIT complex-dependent regulation of cell-matrix signaling. Mol Cell Biol 2010;30:1971-83.

55 Yang Z, Rayala S, Nguyen D, et al. Pak1 phosphorylation of snail, a master regulator of epithelial-to-mesenchyme transition, modulates snail's subcellular localization and functions. Cancer Res 2005;65:3179-84.

56 Paliouras GN, Naujokas MA, Park M. Pak4, a novel Gab1 binding partner, modulates cell migration and invasion by the Met receptor. Mol Cell Biol 2009:29:3018-32.

57 Singh RR, Song C, Yang Z, et al. Nuclear localization and chromatin targets of p21-activated kinase 1. J Biol Chem 2005;280:18130-7.

58 Lightcap CM, Kari G, Arias-Romero LE, et al. Interaction with LC8 is required for Pak1 nuclear import and is indispensable for zebrafish development. PLoS One 2009:4:e6025.

59 Li Y, Shao Y, Tong Y, et al. Nucleo-cytoplasmic shuttling of PAK4 modulates beta-catenin intracellular translocation and signaling. Biochimica et biophysica acta 2012;1823:465-75.

60 Mazumdar A, Kumar R. Estrogen regulation of Pak1 and FKHR pathways in breast cancer cells. FEBS Lett 2003;535:6-10.

61 Meng Q, Rayala SK, Gururaj AE, et al. Signaling-dependent and coordinated regulation of transcription, splicing, and translation resides in a single coregulator, PCBP1. Proc Natl Acad Sci USA 2007;104:5866-71

62 Baldassa S, Calogero AM, Colombo G, et al. N-terminal interaction domain implicates PAK4 in translational regulation and reveals novel cellular localization signals. J Cell Physiol 2010;224:722-33.

63 Huynh N, Yim M, Chernoff J, et al. p-21-Activated kinase 1 mediates gastrin-stimulated proliferation in the colorectal mucosa via multiple signaling pathways. Am J Physiol Gastrointest Liver Physiol 2013;304:G561-7.

64 McDaniel AS, Allen JD, Park SJ, et al. Pak1 regulates multiple c-Kit mediated Ras-MAPK gain-in-function phenotypes in Nf1+l- mast cells. Blood 2008; 112:4646-54.

65 Qu J, Li X, Novitch BG, et al. PAK4 kinase is essential for embryonic viability and for proper neuronal development. Mol Cell Biol 2003;23:7122-33.

66 Li X, Minden A. PAK4 functions in tumor necrosis factor (TNF) alpha-induced survival pathways by facilitating TRADD binding to the TNF receptor. I Biol Chem 2005:280:41192-200.

67 Wang Z, Fu M, Wang L, et al. p21-Activated Kinase 1 (PAK1) Can Promote ERK Activation in a Kinase-independent Manner. J Biol Chem 2013:288:20093-9. 
68 Jin S, Zhuo Y, Guo W, et al. p21-activated Kinase 1 (Pak1)-dependent phosphorylation of Raf-1 regulates its mitochondrial localization, phosphorylation of BAD, and BCl-2 association. J Biol Chem 2005;280:24698-705.

69 Higuchi M, Onishi K, Kikuchi C, et al. Scaffolding function of PAK in the PDK1-Akt pathway. Nat Cell Biol 2008;10:1356-64.

70 Zhou GL, Zhuo Y, King CC, et al. Akt phosphorylation of serine 21 on Pak1 modulates Nck binding and cell migration. Mol Cell Biol 2003;23:8058-69.

71 Schepers A, Clevers H. Wht signaling, stem cells, and cancer of the gastrointestinal tract. Cold Spring Harb Perspect Biol 2012;4:a007989.

72 Barker N, Ridgway RA, van Es JH, et al. Crypt stem cells as the cells-of-origin of intestinal cancer. Nature 2009;457:608-11.

73 Wu X, Tu X, Joeng KS, et al. Rac1 activation controls nuclear localization of beta-catenin during canonical Wnt signaling. Cell 2008;133:340-53.

74 Park MH, Kim DJ, You ST, et al. Phosphorylation of beta-catenin at serine 663 regulates its transcriptional activity. Biochem Biophys Res Commun 2012;419:543-9.

75 Orsulic S, Huber $\mathrm{O}$, Aberle $\mathrm{H}$, et al. E-cadherin binding prevents beta-catenin nuclear localization and beta-catenin/LEF-1-mediated transactivation. J Cell Sci 1999;112:1237-45.

76 Khare V, Lyakhovich A, Dammann K, et al. Mesalamine modulates intercellular adhesion through inhibition of $\mathrm{p}-21$ activated kinase-1. Biochem Pharmacol 2013:85:234-44.

77 Myant KB, Cammareri P, McGhee EJ, et al. ROS production and NF-kappaB activation triggered by RAC1 facilitate WNT-driven intestinal stem cell proliferation and colorectal cancer initiation. Cell Stem cell 2013;12:761-73.

78 Sanlioglu S, Williams CM, Samavati L, et al. Lipopolysaccharide induces Rac1-dependent reactive oxygen species formation and coordinates tumor necrosis factor-alpha secretion through IKK regulation of NF-kappa B. J Biol Chem 2001;276:30188-98.

79 Napetschnig J, Wu H. Molecular basis of NF-kappaB signaling. Ann Rev Biophy 2013:42:443-68

80 Bhattacharyya S, Borthakur A, Dudeja PK, et al. Lipopolysaccharide-induced activation of NF-kappaB non-canonical pathway requires BCL10 serine 138 and NIK phosphorylations. Exp Cell Res 2010;316:3317-27.

81 Al-Sadi R, Ye D, Said HM, et al. IL-1 beta-induced increase in intestinal epithelial tight junction permeability is mediated by MEKK-1 activation of canonical NF-kappaB pathway. Am J Pathol 2010;177:2310-22.

82 Suzuki T, Yoshinaga N, Tanabe S. Interleukin-6 (IL-6) regulates claudin-2 expression and tight junction permeability in intestinal epithelium. J Biol Chem 2011;286:31263-71.

83 Fan S, Gao M, Meng Q, et al. Role of NF-kappaB signaling in hepatocyte growth factor/scatter factor-mediated cell protection. Oncogene 2005;24:1749-66.

84 Royal I, Lamarche-Vane N, Lamorte L, et al. Activation of cdc42, rac, PAK, and rho-kinase in response to hepatocyte growth factor differentially regulates epithelial cell colony spreading and dissociation. Mol Biol Cell 2000;11:1709-25.

85 Frost JA, Swantek JL, Stippec S, et al. Stimulation of NFkappa B activity by multiple signaling pathways requires PAK1. J Biol Chem 2000;275:19693-9.

86 Neumann M, Foryst-Ludwig A, Klar S, et al. The PAK1 autoregulatory domain is required for interaction with NIK in Helicobacter pylori-induced NF-kappaB activation. Biol Chem 2006;387:79-86.

87 Basak C, Pathak SK, Bhattacharyya A, et al. NF-kappaB- and C/EBPbeta-driven interleukin-1 beta gene expression and PAK1-mediated caspase-1 activation play essential roles in interleukin-1 beta release from Helicobacter pylori lipopolysaccharide-stimulated macrophages. J Biol Chem 2005;280:4279-88.

88 Dammann K, Khare V, Lang M, et al. PAK1 Mediates NF-KB Signaling in Colitis and Colitis-Associated Cancer (abstract). Gastroenterology 2013;144.

89 Frost JA, Xu S, Hutchison MR, et al. Actions of Rho family small $\mathrm{G}$ proteins and p21-activated protein kinases on mitogen-activated protein kinase family members. Mol Cell Biol 1996;16:3707-13.

90 Fang JY, Richardson BC. The MAPK signalling pathways and colorectal cancer. Lancet Oncol 2005;6:322-7.

91 Qing $\mathrm{H}$, Gong W, Che Y, et al. PAK1-dependent MAPK pathway activation is required for colorectal cancer cell proliferation. Tumour Biol 2012;33:985-94.

92 Huynh N, Liu KH, Baldwin GS, et al. P21-activated kinase 1 stimulates colon cancer cell growth and migration/invasion via ERK- and AKT-dependent pathways. Biochim Biophys Acta 2010:1803:1106-13.

93 Vadlamudi RK, Adam L, Wang RA, et al. Regulatable expression of p21-activated kinase-1 promotes anchorage-independent growth and abnormal organization of mitotic spindles in human epithelial breast cancer cells. J Biol Chem 2000;275:36238-44.

94 Glotfelty LG, Hecht GA. Enteropathogenic E. coli effectors EspG1/G2 disrupt tight junctions: new roles and mechanisms. Ann N Y Acad Sci 2012;1258:149-58.

95 Fagundes-Neto U, Kallas MR, Patricio FR. Morphometric study of the small bowel mucosa in infants with diarrhea due to enteropathogenic Escherichia coli strains. Hepatogastroenterology 1997;44:1051-6.

96 Hill SM, Phillips AD, Walker-Smith JA. Enteropathogenic Escherichia coli and life threatening chronic diarrhoea. Gut 1991:32:154-8.

97 Germane KL, Spiller BW. Structural and functional studies indicate that the EPEC effector, EspG, directly binds p21-activated kinase. Biochemistry 2011;50:917-19.
98 Danese S, Fiocchi C. Ulcerative Colitis. N Engl J Med 2011;365:1713-25.

99 Coussens LM, Werb Z. Inflammation and cancer. Nature 2002;420:860-7.

100 Itzkowitz SH, Harpaz N. Diagnosis and management of dysplasia in patients with inflammatory bowel diseases. Gastroenterology 2004;126:1634-48.

101 Lyda MH, Noffsinger A, Belli J, et al. Microsatellite instability and K-ras mutations in patients with ulcerative colitis. Hum Pathol 2000;31:665-71.

102 Cunningham D, Atkin W, Lenz HJ, et al. Colorectal cancer. Lancet 2010;375:1030-47.

103 Hoover WC, Zhang W, Xue Z, et al. Inhibition of p21 activated kinase (PAK) reduces airway responsiveness in vivo and in vitro in murine and human airways. Plos One 2012;7:e42601.

104 Staser K, Shew MA, Michels EG, et al. A Pak1-PP2A-ERM signaling axis mediates $\mathrm{F}$-actin rearrangement and degranulation in mast cells. Exp Hematol 2013;41:56-66.e2.

105 Khare V, Dammann K, Jambrich M, et al. p21-activated kinase-1 in the prevention of inflammation-driven colon cancer (abstract). AACR Meeting Abstracts 2013; 73(Supp 1):3712.

106 Barrett JC, Lee JC, Lees CW, et al.; UK IBD Genetics Consortium. Genome-wide association study of ulcerative colitis identifies three new susceptibility loci, including the HNF4A region. Nat Genet 2009;41:1330-4.

107 Jemal A, Center MM, DeSantis C, et al. Global patterns of cancer incidence and mortality rates and trends. Cancer Epidemiol Biomarkers Prev 2010;19:1893-907.

108 Boland CR, Luciani MG, Gasche C, et al. Infection, inflammation, and gastrointestinal cancer. Gut 2005;54:1321-31.

109 Fearon ER. Molecular genetics of colorectal cancer. Ann Rev Pathol 2011;6:479-507.

110 Carter JH, Douglass LE, Deddens JA, et al. Pak-1 expression increases with progression of colorectal carcinomas to metastasis. Clin Cancer Res 2004; 10:3448-56.

111 Li LH, Zheng MH, Luo Q, et al. P21-activated protein kinase 1 induces colorectal cancer metastasis involving ERK activation and phosphorylation of FAK at Ser-910. Int J Oncol 2010;37:951-62.

112 Gong W, An Z, Wang Y, et al. P21-activated kinase 5 is overexpressed during colorectal cancer progression and regulates colorectal carcinoma cell adhesion and migration. Int J Cancer 2009;125:548-55.

113 He H, Huynh N, Liu KH, et al. P-21 activated kinase 1 knockdown inhibits beta-catenin signalling and blocks colorectal cancer growth. Cancer Lett 2012;317:65-71.

114 Menzel N, Melzer J, Waschke J, et al. The Drosophila p21-activated kinase Mbt modulates DE-cadherin-mediated cell adhesion by phosphorylation of Armadillo. Biochem J 2008:416:231-41.

115 Taurin S, Sandbo N, Qin Y, et al. Phosphorylation of beta-catenin by cyclic AMP-dependent protein kinase. J Biol Chem 2006;281:9971-6.

116 Yuen ST, Davies H, Chan TL, et al. Similarity of the phenotypic patterns associated with BRAF and KRAS mutations in colorectal neoplasia. Cancer Res 2002;62:6451-5.

117 Fransen $\mathrm{K}$, Klintenas $\mathrm{M}$, Osterstrom $\mathrm{A}$, et al. Mutation analysis of the BRAF, ARAF and RAF-1 genes in human colorectal adenocarcinomas. Carcinogenesis 2004;25:527-33.

118 Balmanno K, Chell SD, Gillings AS, et al. Intrinsic resistance to the MEK1/2 inhibitor AZD6244 (ARRY-142886) is associated with weak ERK1/2 signalling and/ or strong PI3K signalling in colorectal cancer cell lines. Int I Cancer 2009;125:2332-41.

119 Liu KH, Huynh N, Patel O, et al. P21-activated kinase 1 promotes colorectal cancer survival by up-regulation of hypoxia-inducible factor-1alpha. Cancer Lett 2013:340:22-9.

120 Korsse SE, Peppelenbosch MP, van Veelen W. Targeting LKB1 signaling in cancer. Biochimica et biophysica acta 2013;1835:194-210.

121 Deguchi A, Miyoshi H, Kojima Y, et al. LKB1 suppresses p21-activated kinase-1 (PAK1) by phosphorylation of Thr109 in the p21-binding domain. J Biol Chem 2010;285:18283-90.

122 Tanwar PS, Kaneko-Tarui T, Zhang L, et al. Altered LKB1/AMPK/TSC1/TSC2/mTOR signaling causes disruption of Sertoli cell polarity and spermatogenesis. Hum Mol Genet 2012;21:4394-405.

123 Gu S, Kounenidakis M, Schmidt EM, et al. Rapid activation of FAK/mTOR/p70S6K/ PAK1-signaling controls the early testosterone-induced actin reorganization in colon cancer cells. Cell Signal 2013;25:66-73.

124 Lindstrom $E$, Chen $D$, Norlen $P$, et al. Control of gastric acid secretion:the gastrin-ECL cell-parietal cell axis. Comp Biochem Physiol A Mollntegr Physiol 2001;128:505-14.

125 Smith AM, Watson SA. Gastrin and gastrin receptor activation: an early event in the adenoma-carcinoma sequence. Gut 2000:47:820-4.

126 Seva C, Dickinson CJ, Yamada T. Growth-promoting effects of glycine-extended progastrin. Science 1994;265:410-12.

127 Todisco A, Ramamoorthy S, Witham T, et al. Molecular mechanisms for the antiapoptotic action of gastrin. Am J Physiol Gastrointest Liver Physiol 2001;280: G298-307.

128 He H, Shulkes A, Baldwin GS. PAK1 interacts with beta-catenin and is required for the regulation of the beta-catenin signalling pathway by gastrins. Biochim Biophys Acta 2008:1783:1943-54. 
129 Grabowska AM, Watson SA. Role of gastrin peptides in carcinogenesis. Cancer Lett 2007;257:1-15.

130 He H, Yim M, Liu KH, et al. Involvement of $\mathrm{G}$ proteins of the Rho family in the regulation of $\mathrm{BCl}-2$-like protein expression and caspase 3 activation by Gastrins. Cell Signal 2008;20:83-93.

131 Hollande F, Blanc EM, Bali JP, et al. HGF regulates tight junctions in new nontumorigenic gastric epithelial cell line. Am J Physiol Gastrointest Liver Physiol 2001;280:G910-G21.

132 Wroblewski LE, Peek RM Jr. Helicobacter pylori in Gastric Carcinogenesis: Mechanisms. Gastroenterol Clin North Am 2013:42:285-98.

133 Churin $\mathrm{Y}$, Kardalinou E, Meyer TF, et al. Pathogenicity island-dependent activation of Rho GTPases Rac1 and Cdc42 in Helicobacter pylori infection. Mol Microbiol 2001;40:815-23.

134 Crew KD, Neugut Al. Epidemiology of gastric cancer. World J Gastroenterol 2006;12:354-62.

135 Tada M, Kanai F, Tanaka Y, et al. Prognostic significance of genetic alterations detected by high-density single nucleotide polymorphism array in gastric cancer. Cancer Sci 2010;101:1261-9.

136 Ahn HK, Jang J, Lee J, et al. P21-activated kinase 4 overexpression in metastatic gastric cancer patients. Transl Oncol 2011;4:345-9.

137 Li LH, Luo Q, Zheng MH, et al. P21-activated protein kinase 1 is overexpressed in gastric cancer and induces cancer metastasis. Oncol Rep 2012;27: 1435-42.

138 Wang JX, Zhou YN, Zou SJ, et al. Correlations of P21-activated kinase 1 expression to clinicopathological features of gastric carcinoma and patients prognosis. Chin J Cancer 2010;29:649-54.

139 Hong S, Lee HJ, Kim SJ, et al. Connection between inflammation and carcinogenesis in gastrointestinal tract: focus on TGF-beta signaling. World J Gastroenterol 2010;16:2080-93.

140 Han SU, Kim HT, Seong DH, et al. Loss of the Smad3 expression increases susceptibility to tumorigenicity in human gastric cancer. Oncogene 2004;23:1333-41.

141 Guo Q, Su N, Zhang J, et al. PAK4 kinase-mediated SCG10 phosphorylation involved in gastric cancer metastasis. Oncogene 2013:1-11.

142 Wong LL, Lam IP, Wong TY, et al. IPA-3 inhibits the growth of liver cancer cells by suppressing PAK1 and NF-kappaB activation. PloS One 2013:8:e68843.

143 Chen L, Liu H, Liu J, et al. Klotho endows hepatoma cells with resistance to anoikis via VEGFR2/PAK1 activation in hepatocellular carcinoma. PLoS One 2013:8:e58413.

$144 \mathrm{Xu}$ J, Liu H, Chen L, et al. Hepatitis B virus X protein confers resistance of hepatoma cells to anoikis by up-regulating and activating p21-activated kinase 1. Gastroenterology 2012;143:199-212.

145 Barry OP, Mullan B, Sheehan D, et al. Constitutive ERK1/2 activation in esophagogastric rib bone marrow micrometastatic cells is MEK-independent. J Biol Chem 2001:276:15537-46.

146 Kato H, Tachimori Y, Watanabe H, et al. Lymph node metastasis in thoracic esophageal carcinoma. J Surg Oncol 1991;48:106-11.

147 Campregher C, Luciani MG, Gasche C. Activated neutrophils induce an hMSH2-dependent G2/M checkpoint arrest and replication errors at a (CA) 13-repeat in colon epithelial cells. Gut 2008;57:780-7.
148 Allen JD, Jaffer ZM, Park SJ, et al. p21-activated kinase regulates mast cell degranulation via effects on calcium mobilization and cytoskeletal dynamics. Blood 2009:113:2695-705

149 Ding J, Knaus UG, Lian JP, et al. The renaturable 69- and 63-kDa protein kinases that undergo rapid activation in chemoattractant-stimulated guinea pig neutrophils are p21-activated kinases. J Biol Chem 1996;271:24869-73.

150 Park SY, Lee JH, Ha M, et al. miR-29 miRNAs activate p53 by targeting p85 alpha and CDC42. Nat Struct Mol Biol 2009:16:23-9.

151 Lang N, Liu M, Tang QL, et al. Effects of microRNA-29 family members on proliferation and invasion of gastric cancer cell lines. Chin J Cancer 2010;29:603-10.

152 Wang Z, Zhang X, Yang Z, et al. MiR-145 regulates PAK4 via the MAPK pathway and exhibits an antitumor effect in human colon cells. Biochem Biophys Res Commun 2012;427:444-9.

153 Ishihara K, Kamata M, Hayashi I, et al. Roles of bradykinin in vascular permeability and angiogenesis in solid tumor. Int Immunopharmacol 2002;2:499-509.

154 Bagheri-Yarmand R, Vadlamudi RK, Wang RA, et al. Vascular endothelial growth factor up-regulation via p21-activated kinase-1 signaling regulates heregulin-beta1-mediated angiogenesis. J Biol Chem 2000;275:39451-7.

155 Jiang J, Liu W, Guo X, et al. IRX1 influences peritoneal spreading and metastasis via inhibiting BDKRB2-dependent neovascularization on gastric cancer. Oncogene 2011:30:4498-508.

156 Lu Y, Yu Y, Zhu Z, et al. Identification of a new target region by loss of heterozygosity at 5 p15.33 in sporadic gastric carcinomas: genotype and phenotype related. Cancer Lett 2005;224:329-37.

157 Guo X, Liu W, Pan Y, et al. Homeobox gene IRX1 is a tumor suppressor gene in gastric carcinoma. Oncogene 2010;29:3908-20.

158 Gomez M, Tybulewicz V, Cantrell DA. Control of pre-T cell proliferation and differentiation by the GTPase Rac-I. Nat Immunol 2000;1:348-52.

159 Tiede I, Fritz G, Strand S, et al. CD28-dependent Rac1 activation is the molecular target of azathioprine in primary human CD4+ T lymphocytes. J Clin Invest 2003;111:1133-45.

160 Longley DB, Allen WL, Johnston PG. Drug resistance, predictive markers and pharmacogenomics in colorectal cancer. Biochim Biophys Acta 2006;1766:184-96.

161 Nheu TV, He $\mathrm{H}$, Hirokawa $\mathrm{Y}$, et al. The K252a derivatives, inhibitors for the PAK MLK kinase family selectively block the growth of RAS transformants. Cancer $J$ 2002:8:328-36.

162 Yi C, Maksimoska J, Marmorstein R, et al. Development of small-molecule inhibitors of the group I p21-activated kinases, emerging therapeutic targets in cancer. Biochem Pharmacol 2010;80:683-9.

163 Porchia LM, Guerra M, Wang YC, et al. 2-amino-N-\{4-[5-(2-phenanthrenyl)-3(trifluoromethyl)-1H-pyrazol-1-yll-phenyl\} acetamide (OSU-03012), a celecoxib derivative, directly targets p21-activated kinase. Mol Pharmacol 2007:72:1124-31.

164 Maksimoska J, Feng L, Harms K, et al. Targeting large kinase active site with rigid bulky octahedral ruthenium complexes. J Am Chem Soc 2008;130:15764-5.

$165 \mathrm{Xu} \mathrm{Y,} \mathrm{Foulks} \mathrm{JM,} \mathrm{Clifford} \mathrm{A,} \mathrm{et} \mathrm{al.} \mathrm{Synthesis} \mathrm{and} \mathrm{structure-activity} \mathrm{relationship} \mathrm{of}$ 2-arylamino-4-aryl-pyrimidines as potent PAK1 inhibitors. Bioorgan Med Chem Lett 2013;23:4072-5.

166 Fu X, Feng J, Zeng D, et al. PAK4 confers cisplatin resistance in gastric cancer cells via PI3K/Akt- and MEK/Erk-dependent pathways. Biosci Rep 2014:59-97. 


\section{Corrections}

Dammann K, Khare V, Gasche C. Tracing PAKs from GI inflammation to cancer. Gut 2014;63:1173-84. This article is now Open Access, under CC-BY NC license.

To cite Gut 2014;63:1368

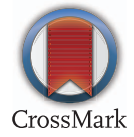

Gut 2014;63:1368. doi:10.1136/gutjnl-2014-306768corr1 